\title{
Comparing Student Performance and Satisfaction in Face-to-Face and Hybrid Formats for a Finance Course
}

\author{
Patricia R. Robertson* \\ Lecturer of Finance Kennesaw State University Coles College of Business, Department of Economics, Finance and Quantitative \\ Kennesaw \\ *Corresponding author: prober16@kennesaw.edu
}

Received January 21, 2014; Revised February 09, 2014; Accepted February 11, 2014

\begin{abstract}
In a study conducted at a large, public university, the author assessed the impact of course delivery method (face-to-face versus hybrid formats) on student performance and satisfaction. The study was based on the concurrent instruction of a senior-level finance course over two semesters. Student performance was based on the percent of students achieving a grade of A, B or C in the course (as opposed to D, F or W/WF) and the scores on the individual gradable assignments. The study shows no significant difference between hybrid and face-to-face delivery in the mean score of student performance. In addition, there was no significant difference in student satisfaction, which was measured based on the official university student survey. The study demonstrates (in contrast to other studies) that student achievement and satisfaction do not significantly differ with hybrid format delivery of the course. Implications of the study's findings are discussed.
\end{abstract}

Keywords: hybrid learning, hybrid format, hybrid course, blended learning

Cite This Article: Patricia R. Robertson, "Comparing Student Performance and Satisfaction in Face-to-Face and Hybrid Formats for a Finance Course.” American Journal of Educational Research, vol. 2, no. 2 (2014): 7377. doi: 10.12691/education-2-2-2.

\section{Introduction}

The popularity and variety of non-traditional course delivery methods has increased in higher education. Students have been receptive to more flexible and convenient learning options. Universities have realized benefits from more efficient utilization of classroom space and leveraging technologies. With the growth of online learning doubling over the last several years, learning delivery methods are continually being explored for viability and effectiveness [4]. The consequential question(s) becomes whether the diverse methods result in the same student learning outcomes and student satisfaction.

The most common course delivery options are categorized into three, broad groupings: face-to-face (F2F), fully-online, and hybrid. The endorsement of hybrid courses has grown in mainstream universities as the best alternative between complete online and face-to-face instruction [2]. These type [hybrid] of courses are becoming more and more the norm in higher education in the United States [8]. This paper directly compare student success and satisfaction between two of these options, F2F and hybrid, under comparable environmental conditions to determine if hybrid, the seeming 'best of both worlds' option, successfully accommodates student and university preferences without sacrificing quality.

The differences between F2F and hybrid delivery are more subtle than fully-online delivery. While F2F is easy to define and consistently executed, there is much variety in how hybrids are designed and executed. The catchall term "hybrid" can include combinations of intermittent, on-campus, classroom sessions coupled with online learning and some inclusion of technology. In the case of this study, "hybrid" (aka blended learning) is defined as regular, weekly, F2F classes for the entire semester. Although the regular interaction between instructor and student is maintained under hybrid, the focus shifts to how compressed classroom time (and how the professor divides learning activities between lecture versus student web-based self-study) impacts student success and satisfaction, if at all.

This study contributes to the evidence on the relative effectiveness of F2F and hybrid methods of course delivery and is preceded by the following literature review. This study appears to have the unique combination of same professor/same semester/same time of day and day of week data linked to a senior-level finance course populated with same major subjects. Given the consistencies between course, timing, instructor, and students, the study focuses on the outcomes associated with course delivery method.

\subsection{Literature Review}

The following literature review includes ten prior studies delving into similar aspects as this study. Comparisons in hypotheses, variables, and conclusions are compared and contrasted. 
Butts (2009) evaluated the results from two courses taught hybrid style and traditional lecture in the sport management curriculum. Course grade was used to measure content mastery. Students identified both desirable and undesirable attributes with hybrid in the official university survey and a subjective evaluation instrument. The study found there was no significant improvement in content mastery. There was a nominal difference in the standardized survey when contrasting teaching techniques. There were differences in student perceptions of the modality, particularly as it related to staying motivated. The traditional courses were delivered a year earlier than the hybrid version, unlike the present study with the courses delivered concurrently.

Utts, et al (2003) compared a traditional offering of elementary statistics with a hybrid offering where the hybrid class met once a week and students were required to learn the material on their own using web-based materials and a textbook. The study examined differences in student performance, student satisfaction, and investment of both student and instructor time. Performance of students in the hybrid offering equaled that of the traditional students, but students in the hybrid were slightly less positive in their subjective evaluation of the course. The results regarding student performance were consistent with the author's findings; however, the results regarding student satisfaction were not consistent with the author's findings. Further, the exam structure was different between the two modalities.

Ranganathan et al (2007) raised the question as to the appropriate proportion of F2Fversus online sessions when the course is taught in a hybrid format. The study observed data from six, independent university studies or websites and discovered wide variations in the mix ranging from $75 \%$ online/25\% F2F to $13 \%$ online/87\% F2F, depending on the institution. It concluded that an equal division of the two resulted in the optimal proportions for three groups of stakeholders: students, professors, and the university. The referenced study only sought to allocate time between the two modalities, and did not mention how the F2F time should be best utilized to maximize student success, what elements and technologies to incorporate into the online portion, or offered data on student success metrics.

Reasons et al (2005) studied student outcomes for two, freshman-level, introductory courses in different academic disciplines (teacher education and health services) with similar pedagogies taught over six terms using all three formats (traditional, internet-based, and hybrid) for the purpose of determining if hybrid was superior to the other options. Outcomes were measured based on course participation, final course grade, and frequency of interaction with the course web site. The research concluded that fully-online could possibly lead to better student outcomes. The study, however, was based on two separate disciplines taught by two separate professors. Also, the study subjects were freshmen, with a wide array of aptitudes, preparedness, and interest levels, compared to the author's subjects, all of which were enrolled in a senior-level, finance elective and were primarily finance majors.

Ward (2004) compared student performance and attitudes in a hybrid teaching model of a elementary statistics course to a traditional (face-to-face) model of the same course. The study concluded there was no significant difference in student performance as measured by grades, which is consistent with the findings in the author's research. However, the results regarding student satisfaction were not consistent. In the Ward study, students preferred the hybrid format and there was no material difference in the author's study. Additionally, the study was based on a required course in the business curriculum so lacked the commonality of the subjects in the author's study who had on common major.

Rivera and Rice (2002) conducted a pilot study on the efficacy of the three class formats (traditional, web-based, and hybrid) in student performance, student satisfaction, and instructor experiences for a junior-level management information systems course. The study found consistency in student performance as measured by test scores for the same exams. However, the results regarding student satisfaction were not consistent with the author's findings, with hybrid students less satisfied with the course. Additionally, the study combined results from two different instructors. Finally, the study was based on a required course in the business curriculum so lacked the commonality of the subjects in the author's study who had on common major.

Black (2002) compared the internet as a learning tool and the extent to which it should be incorporated into the curriculum based on the impact on the student's perception of learning and course satisfaction by comparing traditional, internet, and hybrid courses. The study suggested that the hybrid option may provide the optimal mix for student learning. Unlike the author's study, the results were from the vantage point of the student based on a survey (as opposed to quantifiable course grade and gradable assignment outcomes to assess student learning). Further, rather than connecting the student views to a specific and common course, the survey asked students to reflect on past experiences with the three modalities for courses in which they had previously been enrolled.

Scida and Saury (2006) studied the hybrid format to ascertain the impact on student grades in language instruction. The study concluded that the hybrid format achieved close to the ideal teaching and learning scenario. The discipline (the goal being language mastery), and the hybrid course designed for it, incorporated commercial, integrated, technology-centered tools into the online portion of the course. From this study, the author notes the disconnect between other studies which characterize the 'self-study' portion of a hybrid course as 'online.' While the material might be accessed and distributed online that is not the same as interactive, technology-based (or technology-enhanced) learning (e.g.: threaded discussions, timed exercises and quizzes, self-assessments, drop boxes)or tracking and managing said learning via online systems.

In a proposition paper, Mossavar-Rahmani and LarsonDaugherty (2007) studied a specific structure within which hybrid teaching is delivered to determine if this structure positively impacted course delivery and student success. The focus of the study was on 'communities' and the study suggested that, rather than adding hybrid courses to the existing, onsite course offering, an online studentcentric structure should be designed from the ground up and hybrid courses designed around that structure for 
maximum student engagement. The study offered a specific roadmap for consideration organized at the institutional level. From this study, the author noted the vast disconnect between design and organization of 'hybrid' courses where the only common link is the definition of the modality.

Through a post-assessment, Ernst (2008) compared the cross-group effectiveness of traditional and hybrid teaching in a technology course. The study suggested that questionnaires and surveys, the typical means for capturing student perception of hybrid learning ("microlevel”), did not capture learner understanding (knowledge and skill acquisition). The study included 23 demographically-similar students for each delivery method in the same course with the same instructor. The hybrid group was not aware they were enrolling in a hybrid course, neutralizing self-selection by the student based on preferred learning styles. However, the study was conducted in two different semesters. The study concluded that hybrid courses can remain effective transmitters of information. The study further suggested that hybrid teaching is not widely embraced by faculty and placed the responsibility for a successful outcome on the willingness/readiness of the instructor. The study did not indicate the autonomy through which courses are individually designed by willing and ready instructors to affect consistency in course delivery.

\subsection{Study Background}

The study was conducted at a large, suburban, public university serving 25,000 (+/-) students, $92 \%$ of which are undergraduate and $25 \%$ of which are seeking business discipline degrees. The study is based on data sourced from the same professor concurrently teaching two sections of the same course in the same semester with the same materials and assignments, one of which was conducted with a F2F format and the other a hybrid format (as previously defined). The instructor personally designed and administered the course for eight immediately preceding and contiguous semesters having converted and delivered the course to the hybrid format for the two preceding semesters. Therefore, the course was 'seasoned' prior to the study for both F2F and hybrid delivery.

\subsection{Hypothesis}

Student performance and satisfaction under hybrid course delivery will show no significant difference from F2F course delivery.

\section{Materials and Methods}

\subsection{Subjects and Course Structure}

The semesters for which the data was sourced were standard, 16-week semesters occurring in the fall and included 191 enrolled students with approximately half enrolled in each delivery type. For the purposes of this study, the F2F class met for 75 minutes twice per week in the classroom. The hybrid course met for 75 minutes once per week in the classroom with student self-study for each week's second session. The majority of the hybrid in-class time was utilized introducing topics and concepts with the advanced concepts and problem-solving mastered through student self-study.

\subsection{Study Data and Course Design}

The study data includes two course pairings (one F2F and one hybrid) over two semesters for a total of four sections of the course. For each semester, the course content, textbook, and materials were identical. The materials included power point presentations (some of which were narrated), an array of outside reading and viewing assignments, and a team-based, full semester, cumulative case. The narrated lectures were prepared for approximately a quarter of the course curriculum and were provided to both sections regardless of modality. There was no attendance or participation component in grading.

In both semesters and for both course pairings, the courses were offered during the week at either 3:30 pm or 5:00 pm.

The gradable assignments for the course included four, equally-weighted and spaced, multiple-choice exams which were administered on-campus. In addition, the cumulative, team-based case was assigned at the beginning of the semester and included elements from the entire course. The teams were randomly created by the professor. Non-graded chapter exercises were included for which the solutions were posted for all students. Grades were not curved and no gradable assignment could be dropped nor substituted with other work (such as an optional final). Finally, no extra credit assignments were available that could alter the final grade at the end of the semester.

In addition to consistency in the course type, instructor style and experience, and semesters, the course structure and gradable assignments were also identical within each semester further validating the comparability of the data. The course is an elective in the finance curriculum with the class roster primary comprised of finance and financeinterest majors, which adds to the consistency and reliability of the data.

\subsection{Course Grading Scheme}

The course grading scheme followed the traditional format, as follows, rounded to the nearest whole number (less than .5 rounded down and .5 or greater rounded up):
A: $90-100$
B: $80-89$
C: $70-79$
D: $60-69$
F: Below 60

\section{Results and Discussion}

The course grades and scores from individual gradable assignments were obtained from the author's records and the university's official student record system (Owl Express).

Student and Course Data - Table 1 displays information for the two semesters under study and the combined data. 
Table 1. Student and Course Data

\begin{tabular}{|c|c|c|c|c|c|c|c|c|c|}
\hline & \multicolumn{3}{|c|}{ Fall 2013 } & \multicolumn{3}{c|}{ Fall 2012 } & \multicolumn{3}{c|}{ Both Semesters } \\
\hline & F2F & Hybrid & Total & F2F & Hybrid & Total & F2F & Hybrid & Total \\
\hline \# Students Enrolled & 45 & 48 & 93 & 48 & 50 & 98 & 93 & 98 & 191 \\
\hline \% Finance Majors & $73 \%$ & $81 \%$ & $77 \%$ & $73 \%$ & $74 \%$ & $73 \%$ & $73 \%$ & $78 \%$ & $75 \%$ \\
\hline \% Withdrawals & $4 \%$ & $4 \%$ & $4 \%$ & $2 \%$ & $6 \%$ & $4 \%$ & $3 \%$ & $5 \%$ & $4 \%$ \\
\hline Class Time & $5: 00_{\mathrm{pm}}$ & $3: 30_{\mathrm{pm}}$ & & $3: 30_{\mathrm{pm}}$ & $5: 00_{\mathrm{pm}}$ & & & & \\
\hline Day of Week & $\mathrm{T} / \mathrm{R}$ & $\mathrm{T}$ & & $\mathrm{T} / \mathrm{R}$ & $\mathrm{T}$ & & & & \\
\hline \# Sessions/Week & 2 & 1 & & 2 & 1 & & & & \\
\hline
\end{tabular}

In Fall 2013, subjects included 93 students enrolled in one of the two sections of the finance course (45 in the F2F section and 48 in the hybrid section). Given that the course in the study is a senior-level, finance elective and the majority of the study participants are finance majors, the reliability of the data is strengthened since the aptitude and interest-level of participants is consistent. $77 \%$ of the enrolled students were finance (or finance-interest) majors, $73 \%$ and $81 \%$, respectively, between F2F and hybrid. In both modalities, $4 \%$ of the enrolled students withdrew from the course. For Fall 2012, subject demographics are similar and included 98 students enrolled in one of the two sections of the finance course (48 in the F2F section and
50 in the hybrid section). $73 \%$ of the enrolled students were finance (or finance-interest) majors, $73 \%$ and $74 \%$, respectively, between F2F and hybrid. On average, $4 \%$ of the enrolled students withdrew from the course (2\% and $6 \%$, respectively, between F2F and hybrid). Overall, data from 191 enrolled students was included, equally divided between the two delivery methods, $75 \%$ of which were finance or finance-interest majors.

Grade Distribution - Table 2 present the distribution of the overall course grade and the success rate (percent achieving a grade of $\mathrm{A}, \mathrm{B}$ or $\mathrm{C}$ in the course, as opposed to $\mathrm{D}, \mathrm{F}$ or W/WF) for each delivery method.

Table 2. Grade Distribution

\begin{tabular}{|c|c|c|c|c|c|c|c|c|c|}
\hline & \multicolumn{3}{|c|}{ Fall 2013} & \multicolumn{3}{|c|}{ Fall 2012} & \multicolumn{3}{|c|}{ Both Semesters } \\
\hline Grades & F2F & Hybrid & Avg. & F2F & Hybrid & Avg. & F2F & Hybrid & Avg. \\
\hline A & $18 \%$ & $17 \%$ & $17 \%$ & $33 \%$ & $36 \%$ & $35 \%$ & $26 \%$ & $27 \%$ & $26 \%$ \\
\hline $\mathrm{B}$ & $42 \%$ & $38 \%$ & $40 \%$ & $38 \%$ & $30 \%$ & $34 \%$ & $40 \%$ & $34 \%$ & $37 \%$ \\
\hline $\mathrm{C}$ & $24 \%$ & $33 \%$ & $29 \%$ & $17 \%$ & $20 \%$ & $18 \%$ & $20 \%$ & $27 \%$ & $24 \%$ \\
\hline $\mathrm{D}$ & $4 \%$ & $2 \%$ & $3 \%$ & $8 \%$ & $2 \%$ & $5 \%$ & $6 \%$ & $2 \%$ & $4 \%$ \\
\hline $\mathrm{F}$ & $7 \%$ & $6 \%$ & $6 \%$ & $2 \%$ & $6 \%$ & $4 \%$ & $4 \%$ & $6 \%$ & $5 \%$ \\
\hline W/WF & $4 \%$ & $4 \%$ & $4 \%$ & $2 \%$ & $6 \%$ & $4 \%$ & $3 \%$ & $5 \%$ & $4 \%$ \\
\hline Total & $100 \%$ & $100 \%$ & $100 \%$ & $100 \%$ & $100 \%$ & $100 \%$ & $100 \%$ & $100 \%$ & $100 \%$ \\
\hline Success Rate (A, B, or C) & $\mathbf{8 4 \%}$ & $88 \%$ & $86 \%$ & $88 \%$ & $86 \%$ & $87 \%$ & $86 \%$ & $87 \%$ & $86 \%$ \\
\hline Chi-square & \multirow{2}{*}{\multicolumn{3}{|c|}{.18}} & \multicolumn{3}{|c|}{.04} & & & \\
\hline$p$-value & & & & \multicolumn{3}{|c|}{.83} & & & \\
\hline
\end{tabular}

For Fall 2013, the proportion of students earning the various grades was consistent between modalities. Additionally, the success rates of the F2F students and hybrid students, $84 \%$ and $88 \%$, respectively, were not significantly different (Chi-square $=.18$; $p$-value $=.67$ ). For Fall 2012, the distribution of grades is also consistent between the two delivery methods. The success rates of the F2F students and hybrid students, $88 \%$ and $86 \%$, respectively, were not significantly different (Chi-square $=.04 ; p$-value $=.83$ ). For both semesters, the independent course grades and success rate was consistent at $86 \%$ and 87\%, respectively, between F2F and hybrid, with an average of $86 \%$. Note that the rigor of the gradable assignments was heightened in the Fall 2013 semester, explaining the shift in course grade distribution amongst $\mathrm{A}, \mathrm{B}$, and $\mathrm{C}$.

Exam and Assignment Grades - Table 3 assesses the delivery methods at a more granular level. The course(s) included four exams and a semester-long, team-based, cumulative case.

Table 3. Exam and Assignment Grades

\begin{tabular}{|c|c|c|c|c|c|c|c|c|}
\hline & \multicolumn{9}{|c|}{ Fall 2013 } & \multicolumn{4}{c|}{ Fall 2012 } \\
\hline Exams & F2F & Hybrid & Total & $\boldsymbol{t} / \boldsymbol{p}^{\mathbf{1}}$ & F2F & Hybrid & Total & $\boldsymbol{t} / \boldsymbol{p}^{\mathbf{1}}$ \\
\hline 1 & $77 \%$ & $75 \%$ & $76 \%$ & $.53 / .60$ & $81 \%$ & $81 \%$ & $81 \%$ & $-.04 / .97$ \\
\hline 2 & $83 \%$ & $83 \%$ & $83 \%$ & $.20 / .84$ & $83 \%$ & $83 \%$ & $83 \%$ & $-.03 / .98$ \\
\hline 3 & $79 \%$ & $78 \%$ & $79 \%$ & $.24 / .81$ & $82 \%$ & $81 \%$ & $82 \%$ & $.19 / .85$ \\
\hline 4 & $80 \%$ & $82 \%$ & $81 \%$ & $-.65 / .52$ & $83 \%$ & $82 \%$ & $82 \%$ & $.22 / .83$ \\
\hline Average & $\mathbf{7 9 \%}$ & $\mathbf{8 0} \%$ & $\mathbf{7 9 \%}$ & & $\mathbf{8 2 \%}$ & $\mathbf{8 2 \%}$ & $\mathbf{8 2 \%}$ & \\
\hline Team Case & $85 \%$ & $84 \%$ & $84 \%$ & $.35 / .73$ & $92 \%$ & $91 \%$ & $92 \%$ & $.48 / .64$ \\
\hline
\end{tabular}

$t$ is $t$-statistic and $p$ is $p$-value

As shown in Table 3, for the Fall 2013 semester, the individual exam grades and the cumulative case grade were strikingly consistent, regardless of delivery methods. The $t$-statistic and $p$-values (two-tailed) are displayed for each and lead to the conclusion of no significant difference in the mean score under F2F and hybrid delivery. The table presents the same data for Fall 2012. Once again, the individual exam grades and the cumulative case grade were strikingly consistent, regardless of delivery methods. Again, the $t$-statistic and $p$-values lead to the conclusion of no significant difference in the mean score under the two modalities. As mentioned, the rigor of the gradable assignments was heightened in the Fall 2013 semester.

Student Satisfaction - Table 4 presents data for student satisfaction, the final metric included in the study and is extracted from the official university student survey conducted at the end of each semester. The question selected as a surrogate for student satisfaction was, "Overall, I am satisfied with the course," and ranges from a rating of 1 to 5 , with 5 being the highest. The significance of this final metric is not the quality of the 
scores; rather, the consistency of the scores across the two delivery methods. The percent of the class participating in the survey is presented, and is large enough to represent overall levels of satisfaction.

Table 4. Student Satisfaction

\begin{tabular}{|c|c|c|c|c|c|c|c|c|c|}
\hline & \multicolumn{3}{|c|}{ Fall 2013 } & \multicolumn{3}{|c|}{ Fall 2012 } & \multicolumn{2}{|c|}{ Both Semesters } \\
\hline & F2F & Hybrid & Avg. & F2F & Hybrid & Avg. & F2F & Hybrid & Avg. \\
\hline Survey Rating & 4.7 & 4.6 & 4.7 & 4.6 & 4.6 & 4.6 & 4.7 & 4.6 & 4.6 \\
\hline \% Participation & $93 \%$ & $94 \%$ & $94 \%$ & $77 \%$ & $83 \%$ & $80 \%$ & & \\
\hline
\end{tabular}

The difference between F2F and hybrid was barely distinguishable. For Fall 2013, the average score was 4.7 versus 4.6, respectively, for F2F versus hybrid. In Fall 2012, the average score was 4.6 versus 4.6, respectively, for F2F versus hybrid.

\section{List of Abbreviations}

F2F: Face-to-face

\section{Conclusions}

Colleges and universities are increasing their offerings of non-traditional course delivery formats to attract and retain students who are receptive to alternatives to F2F and to relieve some pressure on classroom scheduling and academic budgets. In a study including 191 students enrolled in the same upper-level, undergraduate finance course in the same semester taught by the same instructor using the same materials, there was no significant difference in student withdrawal rates, grades for individual course exams and assignments, and/or overall course performance. In the standard metric of student success (earning a $\mathrm{C}$ or better) the results were nearly identical for the two individual semesters studied. The collective success rate for the F2F delivery method for the two semesters and 93 students studied was 86\%. The collective success rate for the hybrid delivery method for the two semesters and 98 students studied was $87 \%$. The study results support the conclusion of no significant difference in the mean score of the gradable assignments under the two modalities. Finally, there was no material difference in student satisfaction in answering the question in the official, subjective, and anonymous university student survey, "Overall, I am satisfied with the course."

As hypothesized, given the same environmental conditions and concurrent instruction to hold all else constant, the two delivery methods of F2F and hybrid do not differ in terms of student success and student satisfaction.

Note: Enrollment for both sections of the course was at capacity. Therefore, an admitted weakness in the data is the assumption that each student opted for their desired delivery method that best complemented their unique learning preferences, schedule, and academic work habits/discipline rather than enrolling in the section with availability.

\section{Acknowledgements}

I wish to thank Penny Verhoeven, $\mathrm{PhD}$ for her technical contribution to this project and Victor Wakeling for his professional guidance and constructive recommendations on this project.

\section{References}

[1] Black, G.,"A Comparison of Traditional, Online and Hybrid Methods of Course Delivery,” Journal of Business Administration Online, 1 (1). Spring 2002.

[2] Butts, F., "Evaluation of Hybrid Online Instruction in Sport Management," Online Journal of Distance Learning Administration, 12 (2). 2009.

[3] Ernst, J., "A Comparison of Traditional and Hybrid Online Instructional Presentation in Communication Technology," Journal of Technology Education, 19 (2). Spring 2008.

[4] Mossavar-Rahmani, F. and Larson-Daugherty, C., "Supporting the Hybrid Learning Model: A New Proposition,” MERLOT Journal of Online Learning and Teaching, 3 (1). 67-78. March 2007.

[5] Ranganathan, S., Negash, S., and Wilcox, M., "Hybrid Learning: Balancing Face-To-Face and Online Class Sessions," Proceeding of the 2007 Southern Association for Information Systems Conference, 178-182. 2007.

[6] Reasons, S.,Valadares, K., Slavkin, M., "Questioning The Hybrid Model: Student Outcomes In Different Course Formats,” Journal of Asynchronous Learning Networks, 9 (1). 83-94. March 2005.

[7] Rivera, J. and Rice, M., "A Comparison of Student Outcomes \& Satisfaction Between Traditional \& Web Based Course Offerings," Online Journal of Distance Learning Administration, 5 (3). 2002.

[8] Scida, E. and Saury, R., "Hybrid Courses and Their Impact on Student and Classroom Performance: A Case Study at the University of Virginia," Calico Journal, 23 (3). 517-531. 2006.

[9] Utts, J., Sommer, B., Acredolo, C., Maher, M., and Matthews, H., "A Study Comparing Traditional and Hybrid Internet-Based Instruction in Introductory Statistics Classes," Journal of Statistics Education, 11 (3). 2003.

[10] Ward, B., "The Best of Both Worlds: A Hybrid Statistics Course," Journal of Statistics Education, 12 (3). 2004. 